\title{
$\mathrm{J}$

\section{Isomer-Selective Detection of Hydrogen-Bond Vibrations in the Protonated Water Hexamer}

\author{
Nadja Heine, ${ }^{\dagger}$ Matias R. Fagiani, ${ }^{\dagger}$ Mariana Rossi, ${ }^{\dagger}$ Torsten Wende, $^{\dagger}$ Giel Berden, ${ }^{\dagger}$ Volker Blum, ${ }^{*}{ }^{\dagger}$ \\ and Knut R. Asmis*, ${ }^{\dagger}$ \\ ${ }^{\dagger}$ Fritz-Haber-Institut der Max-Planck-Gesellschaft, Faradayweg 4-6,14195 Berlin, Germany \\ ${ }^{\ddagger}$ Radboud University Nijmegen, Institute for Molecules and Materials, FELIX Facility, Toernooiveld 7, 6525 ED Nijmegen, The \\ Netherlands
}

\section{Supporting Information}

ABSTRACT: The properties of hydrogen ions in aqueous solution are governed by the ability of water to incorporate ions in a dynamical hydrogen bond network, characterized by a structural variability that has complicated the development of a consistent molecular level description of $\mathrm{H}^{+}(a q)$. Isolated protonated water clusters, $\mathrm{H}^{+}\left(\mathrm{H}_{2} \mathrm{O}\right)_{n}$, serve as finite model systems for $\mathrm{H}^{+}(a q)$, which are amenable to highly sensitive and selective gas phase spectroscopic techniques. Here, we isolate and assign the infrared (IR) signatures of the Zundel-type and Eigen-type isomers of $\mathrm{H}^{+}\left(\mathrm{H}_{2} \mathrm{O}\right)_{6}$, the smallest protonated

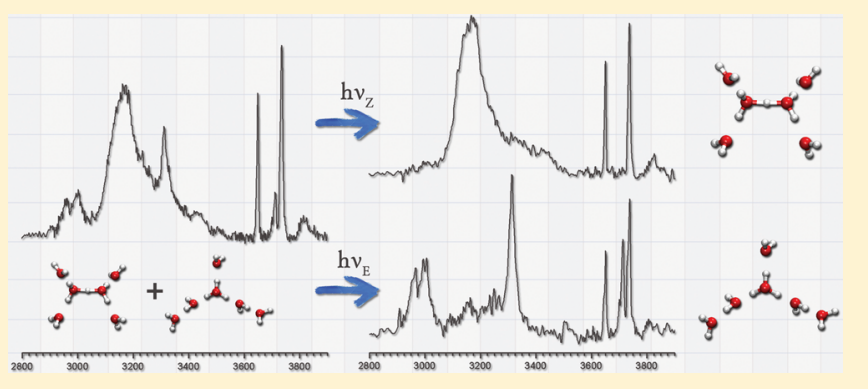
water cluster for which both of these characteristic binding motifs coexist, down into the terahertz spectral region. We use isomer-selective double-resonance population labeling spectroscopy on messenger-tagged $\mathrm{H}^{+}\left(\mathrm{H}_{2} \mathrm{O}\right)_{6} \cdot \mathrm{H}_{2}$ complexes from 260 to $3900 \mathrm{~cm}^{-1}$. Ab initio molecular dynamics calculations qualitatively recover the IR spectra of the two isomers and allow attributing the increased width of IR bands associated with $\mathrm{H}$ bonded moieties to anharmonicities rather than excited state lifetime broadening. Characteristic hydrogen-bond stretching bands are observed below $400 \mathrm{~cm}^{-1}$.

\section{INTRODUCTION}

A consistent molecular level description of the properties of the hydrogen ion in water, $\mathrm{H}^{+}(a q)$, in particular of its role in proton transfer in chemical and biological systems, remains elusive, even though it has captivated scientists for more than 200 years. ${ }^{1}$ A prominent example is its infrared (IR) spectrum, which consists of a combination of a few discrete absorption bands on top of a continuous broad absorption across the entire IR spectrum. Neither the concepts of a symmetrically solvated hydronium ion, $\mathrm{H}_{9} \mathrm{O}_{4}{ }^{+}(a q)$, proposed by Eigen, ${ }^{2}$ the equally shared proton in the Zundel ion, $\mathrm{H}_{5} \mathrm{O}_{2}{ }^{+}(a q),{ }^{3}$ nor models involving the rapid interconversion between these two structural motifs ${ }^{4}$ seem to satisfactorily explain this characteristic IR fingerprint of $\mathrm{H}^{+}(a q)$. In an attempt to resolve this issue, Stoyanov et al. have recently put forth the notion of a stable $\mathrm{H}^{+}\left(\mathrm{H}_{2} \mathrm{O}\right)_{6}(a q)$ species, a Zundel-type ion in the sense that the proton is equally shared between two water molecules, but with more charge delocalization and consequently an unusually long central $\mathrm{O} \cdots \mathrm{O}$ distance. ${ }^{5}$ Recent molecular dynamics simulations, on the other hand, suggest, a distorted, nonsymmetric Eigen-type cation rests at the heart of a dynamical electronic charge defect spanning multiple water molecules. 6

While it remains difficult to pinpoint characteristic binding motifs of interconverting species in aqueous solution experimentally, these can be isolated, stabilized and charac- terized in the form of gas phase clusters. Just as neutral water clusters $^{7,8}$ represent finite model systems for water in its different forms, protonated water clusters serve as prototypes for $\mathrm{H}^{+}(a q)$. The potential energy (PE) landscape of these isolated clusters can be accurately probed with sensitive and selective gas phase spectroscopic techniques, ${ }^{9,10}$ delivering, for example, data for the development of accurate interaction potentials. Here, we apply infrared double-resonance population labeling $\left(\mathrm{IR}^{2} \mathrm{MS}^{2}\right)$ spectroscopy ${ }^{11,12}$ to shed new light on the PE surface of the protonated water hexamer, $\mathrm{H}^{+}\left(\mathrm{H}_{2} \mathrm{O}\right)_{6}$, in the vicinity of the minima corresponding to the Eigen-type (6E) and Zundel-type (6Z) isomers (see Figure 1).

$\mathrm{H}^{+}\left(\mathrm{H}_{2} \mathrm{O}\right)_{6}$ is chosen because it represents the smallest protonated water cluster for which both of these characteristic binding motifs coexist. ${ }^{13,14}$ We also directly probe low-energy hydrogen-bond $(\mathrm{HB})$ vibrations of protonated water clusters for the first time. A precise characterization of the PE surface supporting the "librational" and "translational" IR bands is critical for understanding HB network rearrangement dynamics ultimately leading to proton transfer and serves as a sensitive test for quantum chemical calculations. ${ }^{7,8}$ Since anharmonic effects are known to play a critical role in protonated water

Received: February 12, 2013

Published: May 12, 2013 


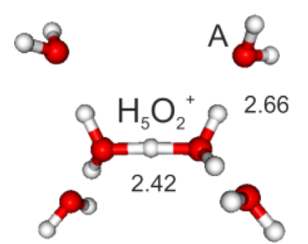

$6 Z$

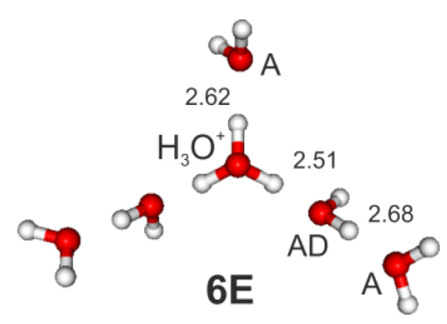

Figure 1. DFT PBE+vdW local minimum energy structures of the Zundel-type $(6 \mathrm{Z})$ and Eigen-type $(6 \mathrm{E})$ isomers of $\mathrm{H}^{+}\left(\mathrm{H}_{2} \mathrm{O}\right)_{6}$. Water molecules are classified according to their function as $\mathrm{HB}$ acceptor (A) and donor (D). O $\cdots \mathrm{O}$ distances are given in $\AA$.

clusters (see, for example, refs 15-20 and refs therein), we make use of ab initio molecular dynamics (AIMD) simulations.

The most detailed structural information on how hydrogen ions are hydrated in finite systems is gained from IR experiments on $\mathrm{H}^{+}\left(\mathrm{H}_{2} \mathrm{O}\right)_{n}$ clusters. ${ }^{10,13,14,21-28}$ In order to identify the signal carrier, the clusters are size-selected, which reduces their number density and typically prohibits direct absorption measurements. Instead, photoabsorption is measured indirectly by monitoring the photodissociation yield. For smaller clusters $(n<6)$ either Zundel-type $(n=2)$ or Eigentype $(n=3-5)$ structures have been reported. ${ }^{10,13,22,26,28-31}$ $\mathrm{H}^{+}\left(\mathrm{H}_{2} \mathrm{O}\right)_{6}$ is the smallest protonated water cluster for which both binding motifs coexist ${ }^{13,14}$ and thus represents a prototypical system for studying structure-dependent charge delocalization on a single $\mathrm{PE}$ surface. The gas phase IR spectroscopy of the isomeric mixture of $\mathrm{H}^{+}\left(\mathrm{H}_{2} \mathrm{O}\right)_{6}$ has been studied only in the $\mathrm{O}-\mathrm{H}$ stretching region above 2400 $\mathrm{cm}^{-1} \cdot{ }^{13,14}$ In addition, the IR spectrum of the (Ar-tagged) Zundel-type isomer has been reported down to $1000 \mathrm{~cm}^{-1}$, the region of the characteristic absorption bands of the equally shared proton. ${ }^{30}$ Thus, large parts of the PE surface of $\mathrm{H}^{+}\left(\mathrm{H}_{2} \mathrm{O}\right)_{6}$ have remained experimentally unexplored. This includes most of the fingerprint vibrations of the Eigen-type isomers and, more importantly, the $\mathrm{HB}$ vibrations of both species, which play a central role in the $\mathrm{HB}$ rearrangement dynamics in these model systems. Here, we extend these studies down to $260 \mathrm{~cm}^{-1}$, directly probing the interaction of an ion with its hydration shell(s). We measure the IR spectra of the coexisting Zundel-type and Eigen-type isomers individually using $\mathrm{IR}^{2} \mathrm{MS}^{2}$ spectroscopy, ${ }^{11,12,32,33}$ a particularly attractive variant of ion dip spectroscopy, ${ }^{34-38}$ because it does not require the presence of a UV-vis chromophore in the cluster. Instead, this detection technique makes use of two tunable IR lasers in combination with two stages of mass separation (MS), hence the abbreviation $\mathrm{IR}^{2} \mathrm{MS}^{2}$.

The reliable assignment of IR bands to specific isomers typically requires that gas phase IR photodissociation spectra are measured of (internally) cold clusters in the linear absorption regime, such that observed band positions and intensities can be directly compared with predicted ones from quantum chemical calculations. Since smaller protonated water clusters $(n \leq 7)$ have dissociation energies of at least $45 \mathrm{~kJ} / \mathrm{mol}$ $\left(3740 \mathrm{~cm}^{-1}\right),{ }^{39,40}$ single-photon photodissociation experiments across large parts of the IR spectrum cannot be performed on the bare, cold clusters. Hence, the messenger technique ${ }^{41}$ is used to measure vibrational spectra of colder species in the linear absorption regime. ${ }^{10,14,26,28}$ However, charge delocalization in hydrated proton clusters is very sensitive to changes in the hydration shell environment, and addition of messenger species can have a marked effect on the isomer distribution. ${ }^{14,42}$ For example, addition of an Ar atom, commonly used as a messenger species, particularly stabilizes the Zundel-type isomer for $n=6$ and $n=7$, such that only these isomers are observed in the Ar-predissociation spectra. ${ }^{10,14,28}$ Mizuse et al. have shown that $\mathrm{H}_{2}$-tagging is similarly efficient compared to Ar-tagging, but less distorting, and the $\mathrm{H}_{2}$-tagged clusters therefore better reflect the isomer distribution of the bare cluster. ${ }^{14}$ In the present study we therefore use $\mathrm{H}_{2}$ as a messenger and form the tagged complexes in a buffer-gas-filled, cryogenically cooled ion trap held at $15 \mathrm{~K}$.

\section{EXPERIMENTAL SECTION}

2.1. Experimental Setup. The infrared (IR) photodissociation experiments are carried out using the Berlin ion trap-tandem mass spectrometer ${ }^{43,44}$ enhanced by a custom-built $180^{\circ}$ reflectron stage (see Figure 2). The instrument was temporarily installed at the Free

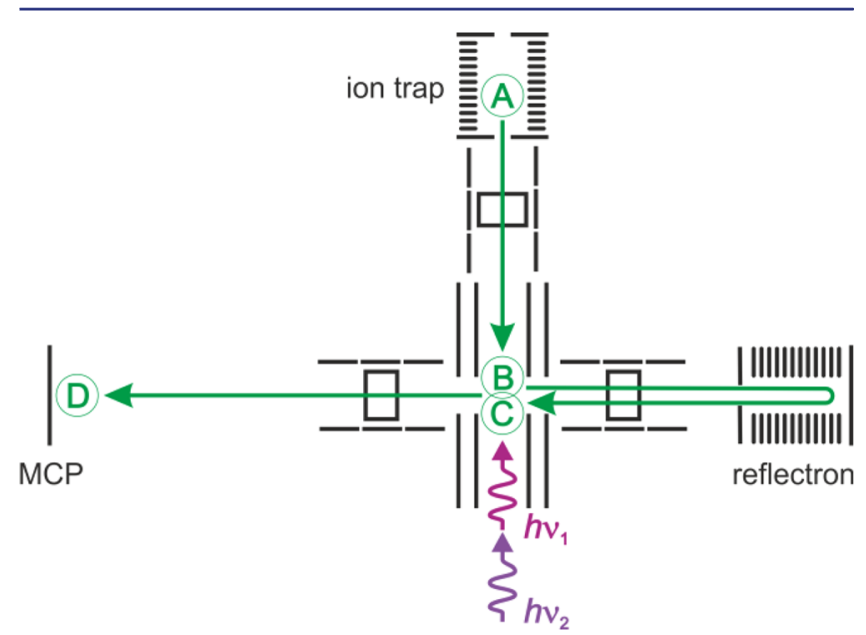

Figure 2. Scheme of the $\mathrm{IR}^{2} \mathrm{MS} \mathrm{S}^{2}$ experimental setup. Ions are extracted from the ion trap (A) and focused into the extraction zone of a reflectron-TOF mass spectrometer. After irradiation by the first IR laser pulse $\left(h \nu_{1}\right)$, ions are accelerated into the $180^{\circ}$ reflectron stage (B) and refocused. The second IR laser pulse $\left(h \nu_{2}\right)$ is timed such as to optimize temporal overlap with the parent ion packet. Ions are reaccelerated into the linear TOF section (C), and a TOF mass spectrum is measured at the MCP detector (D).

Electron Laser for Infrared eXperiments (FELIX) facility ${ }^{45}$ in The Netherlands. The $\mathrm{IR}^{2} \mathrm{MS} \mathrm{S}^{2}$ experiments make use of the tunable IR radiation from FELIX $\left(260-2000 \mathrm{~cm}^{-1}\right)$ in combination with the onsite Laservision OPO/OPA IR laser ${ }^{46}\left(2050-3900 \mathrm{~cm}^{-1}\right)$, both operated at $10 \mathrm{~Hz}$. Additional experiments above $2050 \mathrm{~cm}^{-1}$ were performed in Berlin using two Laservision OPO/OPA IR lasers. The bandwidth of the FELIX pulses was $\sim 0.2 \%$ RMS of the central wavelength and that of the OPO/OPA laser pulses $2-3 \mathrm{~cm}^{-1}$. IR pulse energies were kept $<10 \mathrm{~mJ}$ to avoid saturation. The photodissociation cross section $\sigma$ was determined from the relative abundances of parent and photofragment ions, $I_{0}$ and $I(\nu)$, and the frequency-dependent laser fluence $F(\nu)$ using $\sigma=-\ln \left[I(\nu) / I_{0}\right] / F(\nu)$. At very low laser fluence this normalization procedure introduces noise to the spectra (see, for example, the $2050-2300 \mathrm{~cm}^{-1}$ region in Figure 3 ).

Protonated water clusters were produced by electrospray of a 10 $\mathrm{mM} \mathrm{HNO}_{3}$ solution in a 1:4 water/acetonitrile mixture. The ion beam was collimated in a He-filled radio frequency (RF) ion guide, and $\mathrm{H}^{+}\left(\mathrm{H}_{2} \mathrm{O}\right)_{6}$ ions were mass-selected in a quadrupole mass filter, deflected by $90^{\circ}$, and focused into a RF ring electrode ion trap. To allow for continuous ion loading, ion thermalization, and ion $-\mathrm{H}_{2}$ complex formation, the trap was continuously filled with $\mathrm{H}_{2}$ buffer gas at $15 \mathrm{~K} \cdot \mathrm{H}^{+}\left(\mathrm{H}_{2} \mathrm{O}\right)_{6} \cdot \mathrm{H}_{2}$ complexes are stabilized through three-body 


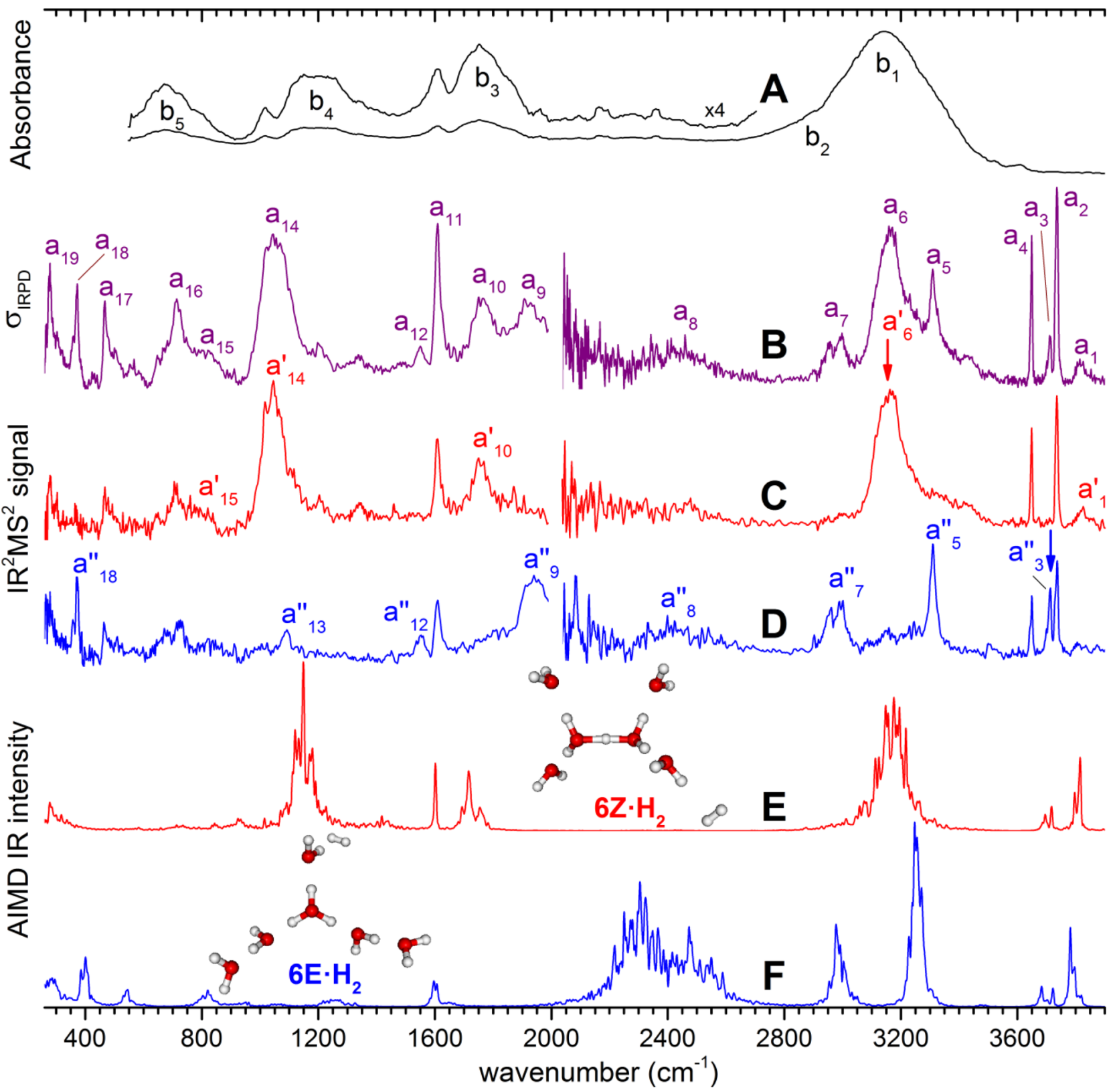

Figure 3. Solution phase IR absorption spectrum of the $\mathrm{H}^{+}(a q)$ ion in ionized strong aqueous acids from ref 5 (A, black), gas phase $\mathrm{H}_{2}-$ predissociation spectrum of $\mathrm{H}^{+}\left(\mathrm{H}_{2} \mathrm{O}\right)_{6} \cdot \mathrm{H}_{2}$ (B, purple), $\mathrm{IR}^{2} \mathrm{MS}^{2}$ spectra of $\mathrm{H}^{+}\left(\mathrm{H}_{2} \mathrm{O}\right)_{6} \cdot \mathrm{H}_{2}$, obtained by probing either the transition indicated by the red $\left(\mathrm{C}, 3159 \mathrm{~cm}^{-1}\right)$ or the blue $\left(\mathrm{D}, 3715 \mathrm{~cm}^{-1}\right)$ arrow, and anharmonic IR spectra of $6 \mathrm{Z} \cdot \mathrm{H}_{2}\left(\mathrm{E}\right.$, red) and $6 \mathrm{E} \cdot \mathrm{H}_{2}(\mathrm{~F}$, blue $)$ obtained from PBE+vdW AIMD simulations at $50 \mathrm{~K}$, from 260 to $3900 \mathrm{~cm}^{-1}$. Spectra B-D each consist of two traces, corresponding to separate measurements in the scanning range of the IR-FEL $\left(260-2000 \mathrm{~cm}^{-1}\right)$ and the IR-OPO/OPA laser $\left(2050-3900 \mathrm{~cm}^{-1}\right)$. Experimental bands are labeled (see Table 1 for band positions and assignments).

collisions. ${ }^{47,48}$ Every $100 \mathrm{~ms}$ all ions were extracted from the trap (Figure 2, A) and focused both temporally and spatially into the center of the extraction region of an orthogonally mounted reflectron-linear time-of-flight (TOF) tandem mass spectrometer. Here, the parent ions, $\mathrm{H}^{+}\left(\mathrm{H}_{2} \mathrm{O}\right)_{6} \cdot \mathrm{H}_{2}$, were irradiated with the first IR laser pulse, producing a first set of photofragment ions (Figure 2, B). Subsequently, all ions were accelerated into the $180^{\circ}$ reflectron stage by application of a first set of high voltage pulses. They separated out in time and space according to their mass/charge ratio and were refocused at the original interaction zone. The second (probe) laser pulse was timed such that temporal overlap with the parent ion packet was optimized, producing a second set of photofragment ions (Figure $2, \mathrm{C})$. All ions in-between the acceleration plates were reaccelerated (in the opposite direction) into a second linear TOF stage of the mass spectrometer by a second set of high voltage pulses. For each laser shot, a TOF mass spectrum was measured (Figure 2, D), which contains (at least) three separate ion signals, corresponding to the parent ions, fragment ions from the first IR laser pulse and the fragment ions from the second IR laser pulse. $I^{2} M S^{2}$ spectra are recorded by tuning the wavelength of the probe laser to an isomerspecific transition and monitoring all ion intensities as the laser wavelength of the first laser is scanned (50-100 measurements per wavelength step). ${ }^{11}$

2.2. Computational Details. The density functional theory (DFT) calculations were performed with the all-electron, localized basis FHI-aims program package. ${ }^{49}$ We used the $\mathrm{PBE}^{50}$ semilocal exchange-correlation functional corrected with a $\mathrm{C}_{6}[n] / \mathrm{R}^{6}$ term (as proposed in ref 51) in order to account for van der Waals dispersion interactions, which we call PBE+vdW. We used tight settings for basis sets and numerical grids, as detailed in ref 49 . These settings yield 
Table 1. Position (in $\mathrm{cm}^{-1}$ ) and Assignment of the Vibrational Bands Observed in the IR Spectra of $\mathrm{H}^{+}\left(\mathrm{H}_{2} \mathrm{O}\right)_{6} \cdot \mathrm{H}_{2}$

\begin{tabular}{|c|c|c|c|c|c|}
\hline & $\operatorname{IR}^{2} \mathrm{MS}^{2}\left(3159 \mathrm{~cm}^{-1}\right)$ & $\operatorname{IR}^{2} \mathrm{MS}^{2}\left(3715 \mathrm{~cm}^{-1}\right)$ & previous exp. & isomer & assignment $^{d}$ \\
\hline $3815\left(a_{1}\right)$ & $3827\left(a_{1}^{\prime}\right)$ & & $3817^{a}$ & $\mathrm{Z}$ & combination band \\
\hline $3737\left(\mathrm{a}_{2}\right)$ & $3737\left(\mathrm{a}_{2}^{\prime}\right)$ & $3738\left(a^{\prime \prime}{ }_{2}\right)$ & $3741^{a}, 3740^{b}, 3739^{c}$ & $\mathrm{Z}, \mathrm{E}$ & free $\mathrm{O}-\mathrm{H}$ stretch (antisym, A- $\mathrm{H}_{2} \mathrm{O}$ ) \\
\hline $3713\left(a_{3}\right)$ & & $3714\left(\mathrm{a}_{3}{ }_{3}\right)$ & $3713^{a}, 3716^{c}$ & $\mathrm{E}$ & free $\mathrm{O}-\mathrm{H}$ stretch $\left(\mathrm{AD}-\mathrm{H}_{2} \mathrm{O}\right)$ \\
\hline $3651\left(a_{4}\right)$ & $3651\left(a^{\prime}{ }_{4}\right)$ & $3651\left(\mathrm{a}_{4}{ }_{4}\right)$ & $3651^{a}, 3650^{b}, 3652^{c}$ & $\mathrm{Z}, \mathrm{E}$ & free $\mathrm{O}-\mathrm{H}$ stretch $\left(\mathrm{sym}, \mathrm{A}-\mathrm{H}_{2} \mathrm{O}\right)$ \\
\hline $3312\left(a_{5}\right)$ & & $3312\left(a_{5}{ }_{5}\right)$ & $3320^{a}, 3304 / 3325^{c}$ & $\mathrm{E}$ & $\mathrm{O}-\mathrm{H}$ stretch $\left(\mathrm{AD}-\mathrm{H}_{2} \mathrm{O}\right)$ \\
\hline $3163\left(a_{6}\right)$ & $3167\left(\mathrm{a}_{6}^{\prime}\right)$ & & $3178^{a}, 3160^{b}, 3160^{c}$ & $\mathrm{Z}$ & $\mathrm{O}-\mathrm{H}$ stretch $\left(\mathrm{H}_{5} \mathrm{O}_{2}^{+}\right)$ \\
\hline \multirow[t]{2}{*}{$3003\left(a_{7}\right)$} & & $3007\left(a^{\prime \prime}\right)$ & $2988^{a}, 2991^{c}$ & $\mathrm{E}$ & $\mathrm{O}-\mathrm{H}$ stretch $\left(\mathrm{H}_{3} \mathrm{O}^{+}\right)$ \\
\hline & $\sim 2480\left(\mathrm{a}_{8}^{\prime}\right)$ & & & $\mathrm{Z}$ & \\
\hline$\sim 2425\left(a_{8}\right)$ & & $\sim 2425\left(a^{\prime \prime}{ }_{8}\right)$ & & $\mathrm{E}$ & $\mathrm{O}-\mathrm{H}$ stretch $\left(\mathrm{H}_{3} \mathrm{O}^{+}\right)$ \\
\hline $1917\left(a_{9}\right)$ & & $1951\left(a_{9}^{\prime \prime}\right)$ & & $\mathrm{E}$ & $\mathrm{O}-\mathrm{H}$ stretch $\left(\mathrm{H}_{3} \mathrm{O}^{+}\right)$ \\
\hline $1760\left(\mathrm{a}_{10}\right)$ & $1759\left(\mathrm{a}^{\prime}{ }_{10}\right)$ & & & $\mathrm{Z}$ & shared proton bend $\left(\mathrm{H}_{5} \mathrm{O}_{2}^{+}\right)$ \\
\hline $1618\left(\mathrm{a}_{11}\right)$ & $1618\left(a_{11}^{\prime}\right)$ & $1618\left(a_{11}^{\prime \prime}\right)$ & & $\mathrm{Z}, \mathrm{E}$ & $\mathrm{H}_{2} \mathrm{O}$ bend $\left(\mathrm{A}-\mathrm{H}_{2} \mathrm{O}\right)$ \\
\hline \multirow[t]{2}{*}{$1558\left(\mathrm{a}_{12}\right)$} & & $1561\left(a_{12}^{\prime \prime}\right)$ & & $\mathrm{E}$ & $\mathrm{H}_{2} \mathrm{O}$ bend \\
\hline & & $1097\left(a^{\prime \prime}{ }_{13}\right)$ & & $\mathrm{E}$ & $\mathrm{H}_{3} \mathrm{O}^{+}$umbrella \\
\hline $1049\left(\mathrm{a}_{14}\right)$ & $1050\left(a^{\prime}{ }_{14}\right)$ & & $1055^{b}$ & $\mathrm{Z}$ & shared proton stretch $\left(\mathrm{H}_{5} \mathrm{O}_{2}^{+}\right)$ \\
\hline \multirow[t]{2}{*}{$\sim 805\left(\mathrm{a}_{15}\right)$} & $\sim 805\left(\mathrm{a}_{15}^{\prime}\right)$ & & & $\mathrm{Z}$ & shared proton bend $\left(\mathrm{H}_{5} \mathrm{O}_{2}^{+}\right) / \mathrm{H}_{2} \mathrm{O}$ libration \\
\hline & & $831\left(a^{\prime \prime}{ }_{15}\right)$ & & $\mathrm{E}$ & $\mathrm{H}_{3} \mathrm{O}^{+}$libration \\
\hline $717\left(\mathrm{a}_{16}\right)$ & $708\left(a^{\prime}{ }_{16}\right)$ & $729\left(a^{\prime \prime}{ }_{16}\right)$ & & $\mathrm{Z}, \mathrm{E}$ & $\mathrm{H}_{2} \mathrm{O}$ libration \\
\hline $469\left(a_{17}\right)$ & $469\left(a_{17}^{\prime}\right)$ & $465\left(a^{\prime \prime}{ }_{17}\right)$ & & $\mathrm{Z}, \mathrm{E}$ & $\mathrm{H}_{2} \mathrm{O}$ libration \\
\hline $373\left(a_{18}\right)$ & & $358 / 373\left(\mathrm{a}_{18}^{\prime \prime}\right)$ & & $\mathrm{E}$ & H-bond stretch $\left(\mathrm{AD}-\mathrm{H}_{2} \mathrm{O} \cdots \mathrm{H}_{3} \mathrm{O}^{+}\right)$ \\
\hline $279\left(a_{19}\right)$ & $279\left(a_{19}^{\prime}\right)$ & $279\left(a_{19}^{\prime \prime}\right)$ & & $\mathrm{Z}, \mathrm{E}$ & $\mathrm{H}$-bond stretch/A- $\mathrm{H}_{2} \mathrm{O}$ wag \\
\hline
\end{tabular}

${ }^{a} \mathrm{Bare} \mathrm{H}^{+}\left(\mathrm{H}_{2} \mathrm{O}\right)_{6}$ data from ref $13{ }^{b}$ Ar-predissociation data from ref $10{ }^{c}$ Ne-predissociation data from ref $28{ }^{d} \mathrm{~A}=\mathrm{HB}$ acceptor, $\mathrm{D}=\mathrm{HB}$ donor, sym = symmetric, antisym $=$ antisymmetric.

essentially converged energetics, free of basis set superposition errors. ${ }^{49,52}$ Harmonic vibrations were calculated through finite differences. Anharmonic IR spectra were calculated through the Fourier transform of the dipole autocorrelation function, obtained from microcanonical AIMD (Born-Oppenheimer) runs, using a time step of 0.5 fs. For the $6 \mathrm{Z} \cdot \mathrm{H}_{2}$ and $6 \mathrm{E} \cdot \mathrm{H}_{2}$ isomers we have averaged over 4 and 5 trajectories of 10 ps each, respectively, starting from different thermalized geometries. These initial geometries were taken from a 10 ps long thermalization run at $50 \mathrm{~K}$. We have checked that the isomers remain close to their overall initial geometry throughout the simulations.

\section{RESULTS AND DISCUSSION}

The $\mathrm{H}_{2}$-predissociation spectrum of $\mathrm{H}^{+}\left(\mathrm{H}_{2} \mathrm{O}\right)_{6} \cdot \mathrm{H}_{2}$ in the scanning range of the IR-FEL $\left(260-2000 \mathrm{~cm}^{-1}\right)$ and the IROPO/OPA laser $\left(2050-3900 \mathrm{~cm}^{-1}\right)$ is shown in Figure 3 (trace $\mathrm{B}$ ), with band positions and assignments summarized in Table $1 . \mathrm{H}^{+}\left(\mathrm{H}_{2} \mathrm{O}\right)_{6} \cdot \mathrm{H}_{2}$ absorbs throughout the measured IR spectrum, exhibiting more than 20 absorption bands, of which the most intense ones are labeled $a_{1}$ to $a_{19}$. Several bands are significantly broadened, which has been attributed to shorter excited state life times as a result of faster intramolecular vibrational energy redistribution (IVR) due to hydrogen bonding. ${ }^{26}$ Two complementary IR spectra are obtained using the isomer-selective $\mathrm{IR}^{2} \mathrm{MS}{ }^{2}$ technique (traces $\mathrm{C}$ and $\mathrm{D}$ in Figure 3) indicating two structurally very different absorbing species. Moreover, these two spectra suffice to account for all the IR bands observed in the IR spectrum of the isomeric mixture (trace B). Trace $\mathrm{C}$ was obtained by probing band $\mathrm{a}_{6}{ }_{6}$ $\left(3167 \mathrm{~cm}^{-1}\right)$, corresponding to the $\mathrm{O}-\mathrm{H}$ stretching modes of the two hydrogen-bonded water moieties of the $\mathrm{H}_{5} \mathrm{O}_{2}{ }^{+}$-core in isomer 6Z. Trace $\mathrm{D}$ was obtained by probing band $\mathrm{a}_{3}{ }_{3}(3714$ $\left.\mathrm{cm}^{-1}\right)$, the free $\mathrm{O}-\mathrm{H}$ stretching modes of the two $\mathrm{AD}$ water molecules of $6 \mathrm{E}$ (see Figure 1). Each of these vibrational modes is specific to one of the isomers, and therefore a relatively high isomer selectivity of at least $80 \%$ is observed in the $\mathrm{IR}^{2} \mathrm{MS}^{2}$ spectra. IR $^{2} \mathrm{MS}^{2}$ spectra with similar contrast to those shown in
Figure 3 were obtained when probing the isomer-specific bands $\mathrm{a}^{\prime}{ }_{14}\left(1050 \mathrm{~cm}^{-1}\right)$ and $\mathrm{a}^{\prime \prime}{ }_{9}\left(1951 \mathrm{~cm}^{-1}\right)$, supporting that each selective $\mathrm{IR}^{2} \mathrm{MS}^{2}$ spectrum is due to either Zundel-like or Eigen-like isomers of $\mathrm{H}^{+}\left(\mathrm{H}_{2} \mathrm{O}\right)_{6} \cdot \mathrm{H}_{2}$. For comparison and later discussion, the IR spectrum of the $\mathrm{H}^{+}(a q)$ ion in ionized strong aqueous acids from ref 5 is also shown at the top of Figure 3 (trace A).

In order to aid in the assignment of the IR spectra, we performed AIMD calculations. These explicitly include anharmonic effects and were performed on $\mathrm{H}^{+}\left(\mathrm{H}_{2} \mathrm{O}\right)_{6} \cdot \mathrm{H}_{2}$ as well as $\mathrm{H}^{+}\left(\mathrm{H}_{2} \mathrm{O}\right)_{6}$. In the following discussion we mainly make use of the results including the messenger molecule, because this species was probed in the experiments. Note that the comparison of the results with and without messenger suggests that the overall changes to the IR spectrum are rather small (see Supporting Information). Simulated anharmonic IR spectra at $\langle T\rangle=50 \mathrm{~K}$ of the $6 \mathrm{Z} \cdot \mathrm{H}_{2}$ and $6 \mathrm{E} \cdot \mathrm{H}_{2}$ isomers, derived from AIMD calculations, using the $\mathrm{PBE}^{50}$ semilocal functional corrected for van der Waals (vdW) dispersion interactions, ${ }^{51}$ are also shown in Figure 3 (traces E and F). For the most intense absorption features, we observe a satisfactory and unambiguous qualitative agreement between the $6 \mathrm{Z} \cdot \mathrm{H}_{2}$ and the $6 \mathrm{E} \cdot \mathrm{H}_{2}$ calculated anharmonic spectra (traces $\mathrm{E}$ and $\mathrm{F}$ ) and the experimental $\mathrm{IR}^{2} \mathrm{MS}^{2}$ spectra (traces $\mathrm{C}$ and $\mathrm{D}$ ). The AIMD simulations qualitatively reproduce the experimental band widths and shapes, suggesting that anharmonicity rather than excited state lifetime broadening (as a result of very fast internal vibrational energy redistribution $)^{26}$ is the main cause of the observed broadening. The simulated peak positions are typically shifted to higher energies with respect to experiment in several places. The larger shifts between experiment and theory, especially where the motion of the hydrated proton is involved and in the free $\mathrm{OH}$ stretch region, are commonly attributed to limitations of existing functionals, as well as the neglect of nuclear quantum effects, but there is no question as to the unambiguous qualitative correspondence between 


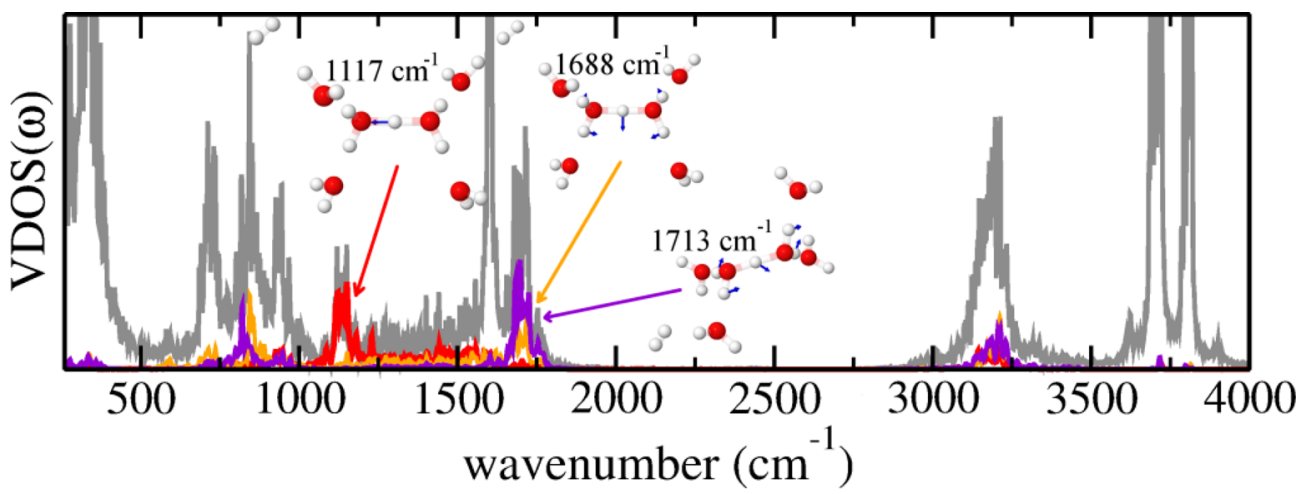

Figure 4. Vibrational density of states (VDOS) obtained from the Fourier transform of the velocity autocorrelation function of a 26 ps long microcanonical AIMD run of $6 \mathrm{Z} \cdot \mathrm{H}_{2}$ with $\langle T\rangle=50 \mathrm{~K}$. In gray, the total VDOS. In red, the projection of the VDOS on the harmonic normal mode that corresponds to the shared proton stretch motion (harmonic frequency at $1117 \mathrm{~cm}^{-1}$ with $\mathrm{PBE}+\mathrm{vdW}$ ). In orange and violet, the projections on harmonic normal modes corresponding to the shared proton bending motion coupled to $\mathrm{HOH}$ bending motions (harmonic frequencies at 1688 and $1713 \mathrm{~cm}^{-1}$, respectively).

experimental and theoretical spectra. In fact, it has been shown by Vendrell et al. ${ }^{53}$ for $\mathrm{H}_{5} \mathrm{O}_{2}{ }^{+}$that such effects can be eliminated completely by probing the complete nuclear PE surface quantum mechanically, but such a treatment is out of the question here because of the computational cost. Note that the simulated spectra of both isomers, $6 \mathrm{Z} \cdot \mathrm{H}_{2}$ and $6 \mathrm{E} \cdot \mathrm{H}_{2}$, exhibit a splitting of the free $\mathrm{O}-\mathrm{H}$ stretching bands $(>3600$ $\mathrm{cm}^{-1}$ ), which is not observed in the experimental spectra. Simulations of the bare clusters $6 \mathrm{Z}$ and $6 \mathrm{E}$ do not yield this splitting and show sharp peaks in good agreement with experiment (see Supporting Information). This indicates that the clusters probed in the experiment have sufficient internal energy to overcome the small barriers separating the basins corresponding to the nearly isoenergetic $\mathrm{H}_{2}$-binding sites, leading to a delocalization of $\mathrm{H}_{2}$ and consequently an averaging-out of this effect, while our simulations, even though of 40 and 50 ps in total, are not long enough for the $\mathrm{H}_{2}$ molecule to explore all possible binding positions.

The $\mathrm{IR}^{2} \mathrm{MS}^{2}$ spectrum of $6 \mathrm{Z} \cdot \mathrm{H}_{2}$ (trace $\mathrm{C}$ ) reveals four characteristically broad absorption bands at $3167\left(\mathrm{a}_{6}^{\prime}\right), 1759$ $\left(a^{\prime}{ }_{10}\right), 1050\left(a^{\prime}{ }_{14}\right)$, and $805 \mathrm{~cm}^{-1}\left(a^{\prime}{ }_{15}\right)$. Their increased width suggests that they all originate from vibrational modes involving the same moiety, namely, the symmetrically hydrated $\mathrm{H}_{5} \mathrm{O}_{2}^{+}$ core. We attribute them to the hydrogen-bonded $\mathrm{O}-\mathrm{H}$ stretching $\left(\mathrm{a}_{6}^{\prime}\right)$ and $\mathrm{H}-\mathrm{O}-\mathrm{H}$ bending $\left(\mathrm{a}^{\prime}{ }_{10}\right)$ modes, as well as a doublet associated with the shared proton stretching mode $\left(\mathrm{a}^{\prime}{ }_{14}, \mathrm{a}^{\prime}{ }_{15}\right)$, which are observed at $\sim 3650,1763,1047$, and 928 $\mathrm{cm}^{-1}$ in bare $\mathrm{H}_{5} \mathrm{O}_{2}^{+}$and whose assignment is widely accepted now. ${ }^{19,29,31,53}$ The increased charge delocalization in $\mathrm{H}_{5} \mathrm{O}_{2}{ }^{+}\left(\mathrm{H}_{2} \mathrm{O}\right)_{4}$ compared to $\mathrm{H}_{5} \mathrm{O}_{2}{ }^{+}$thus results in a pronounced shift to lower energies of bands $\mathrm{a}^{\prime}{ }_{6}$, while bands $\mathrm{a}^{\prime}{ }_{10}$ and $\mathrm{a}^{\prime}{ }_{14}$ remain nearly unaffected. If the effective shared proton frequency corresponds to the centroid of the observed doublet $\left(a^{\prime}{ }_{14}, a^{\prime}{ }_{15}\right),{ }^{54}$ this is also red-shifted in agreement with an increase of the proton affinity of the waters sharing the proton in $\mathrm{H}_{5} \mathrm{O}_{2}^{+}\left(\mathrm{H}_{2} \mathrm{O}\right)_{4}$ compared to $\mathrm{H}_{5} \mathrm{O}_{2}^{+}$as a result of cooperativity.

The characteristic IR fingerprint of the symmetrically hydrated Zundel ion, i.e., bands $\mathrm{a}_{6}^{\prime}{ }_{6}, \mathrm{a}^{\prime}{ }_{10}, \mathrm{a}^{\prime}{ }_{14}$ and $\mathrm{a}^{\prime}{ }_{15}$ in Figure 3 , appears to be qualitatively reproduced by the anharmonic calculations (see trace $\mathrm{E}$ ). Moreover, the intensity ratio of bands $\mathrm{a}^{\prime}{ }_{14}$ and $\mathrm{a}^{\prime}{ }_{10}$, associated with the shared proton stretching and bending modes, is in excellent agreement with the predictions from theory. In contrast, recent molecular dynamics simulations ${ }^{55}$ find the main IR intensity of the proton transfer mode in $\mathrm{H}_{5} \mathrm{O}_{2}^{+}\left(\mathrm{H}_{2} \mathrm{O}\right)_{4}$ at $1750 \mathrm{~cm}^{-1}$, with only little intensity around $1100 \mathrm{~cm}^{-1}$. To test this prediction, we calculated the total vibrational density of states (VDOS), defined as the Fourier transform of the velocity autocorrelation function, from an AIMD run of the $6 \mathrm{Z} \cdot \mathrm{H}_{2}$ isomer, as well as its projection into the well-defined harmonic normal modes. The results, shown in Figure 4, confirm that the intense peak at $1135 \mathrm{~cm}^{-1}$ found in the PBE+vdW anharmonic IR spectra, corresponding to $\mathrm{a}^{\prime}{ }_{14}$ in the experiment, is essentially due only to the shared proton stretch motion (red trace in Figure 4). The peaks around 1700 $\mathrm{cm}^{-1}$, corresponding to $\mathrm{a}^{\prime}{ }_{10}$ in experiment, instead, owe most of their intensity to bending motions of the shared proton coupled to the internal $\mathrm{H}-\mathrm{O}-\mathrm{H}$ bending motions (violet and orange traces in Figure 4). We must, however, comment separately on the $\mathrm{a}^{\prime}{ }_{15}$ feature and its calculated counterpart structure in the 6Z. $\mathrm{H}_{2}$ isomer. In the bare Zundel ion $\left(\mathrm{H}_{5} \mathrm{O}_{2}{ }^{+}\right)$, a structure in the same wavenumber region arises purely because of anharmonic mode couplings, with no harmonic counterpart. ${ }^{15,16,19}$ In contrast, there are corresponding harmonic modes in this region for the hydrated Zundel ion studied here $\left(6 \mathrm{Z} / 6 \mathrm{Z} \cdot \mathrm{H}_{2}\right.$ isomer; see Figure S2, Table S3, and Figure S4 in the Supporting Information). In the AIMD-calculated spectra (Trace E in Figure 3), there is indeed some statistically relevant intensity in this range. Its structure emerges clearly when enhanced by a factor of 5 (Figure S2, Supporting Information). Interestingly, especially its highest-lying component (just below $1000 \mathrm{~cm}^{-1}$ in the calculations) is not simply due to a corresponding harmonic mode, but contains significant contributions from very different modes as well (VDOS decomposition in Figure S3, Supporting Information). The $\mathrm{a}^{\prime}{ }_{15}$ structure is thus analogous to what is known as the lower doublet peak of the bare Zundel ion, but not identical, since a corresponding harmonic contribution exists as well. Note that the coupling of the shared proton stretching and bending modes increases with temperature and has been predicted to be significant at room temperature. ${ }^{56}$ The remaining three narrower bands above $1500 \mathrm{~cm}^{-1}$ observed in trace $\mathrm{C}$ are then assigned to vibrational modes involving the terminal water molecules (see Table 1). These are the free $\mathrm{O}-\mathrm{H}$ stretching $\left(a_{2}^{\prime}, a_{4}^{\prime}\right)$ and the $\mathrm{H}_{2} \mathrm{O}$ bending $\left(a^{\prime}{ }_{11}\right)$ modes.

At least eight characteristic bands are observed in the $\mathrm{IR}^{2} \mathrm{MS}^{2}$ spectrum associated with structure $6 \mathrm{E} \cdot \mathrm{H}_{2}$ (trace D in Figure 3 ). Only three of these have been reported previously (see Table 
1). ${ }^{13}$ These are the free $\left(a^{\prime \prime}{ }_{3}\right)$ and hydrogen-bonded $\left(a^{\prime \prime}{ }_{5}\right) \mathrm{O}-$ $\mathrm{H}$ stretching modes of the two $\mathrm{AD}$ water molecules (see Figure 1) above $3200 \mathrm{~cm}^{-1}$, as well as the highest energy $\mathrm{O}-\mathrm{H}$ stretching mode of the $\mathrm{H}_{3} \mathrm{O}^{+}$core $\left(\mathrm{a}^{\prime \prime}{ }_{7}\right)$ at $\sim 3000 \mathrm{~cm}^{-1}$. The remaining two $\mathrm{O}-\mathrm{H}$ stretching modes are expected to be significantly red-shifted, ${ }^{10}$ and we therefore attribute them to the two characteristically broad bands observed at $2425 \mathrm{~cm}^{-1}$ $\left(\mathrm{a}_{8}{ }_{8}\right)$ and $1951 \mathrm{~cm}^{-1}\left(\mathrm{a}_{9}{ }_{9}\right)$. The anharmonic IR spectrum of $6 \mathrm{E} \cdot \mathrm{H}_{2}$ (trace $\mathrm{F}$ in Figure 3 ) qualitatively reproduces nearly all of these features, in particular the varying widths of bands $\mathrm{a}^{\prime \prime}{ }_{2}-$ $\mathrm{a}^{\prime \prime}{ }_{8}$, confirming our assignment of trace $\mathrm{D}$ to the Eigen isomer. The only significant discrepancy between experiment and anharmonic calculations is found for band $\mathrm{a}^{\prime \prime}{ }_{9}$, which is predicted $\sim 400 \mathrm{~cm}^{-1}$ higher in energy. This assignment is in line with previous results for $\mathrm{H}^{+}\left(\mathrm{H}_{2} \mathrm{O}\right)_{3}$. Ar and $\mathrm{H}^{+}\left(\mathrm{H}_{2} \mathrm{O}\right)_{5}$. Ar. Both of these systems exhibit an asymmetrically hydrated $\mathrm{H}_{3} \mathrm{O}^{+}$ core, which is characterized by an $\mathrm{O}-\mathrm{H}$ stretching band redshifted below $2000 \mathrm{~cm}^{-1}\left(1880 \mathrm{~cm}^{-1}\right) \cdot{ }^{10,26}$ Note, the region around $2000 \mathrm{~cm}^{-1}$ is experimentally more difficult to access, because the pulse energies of either laser source used in our experiments are small in this region, leading to lower signal-tonoise ratios. The other two bands above $1000 \mathrm{~cm}^{-1}$ are attributed to an $\mathrm{H}_{2} \mathrm{O}$ bending mode $\left(\mathrm{a}^{\prime \prime}{ }_{12}\right)$ and the $\mathrm{H}_{3} \mathrm{O}^{+}$ umbrella mode $\left(\mathrm{a}^{\prime \prime}{ }_{13}\right)$.

An expanded view of the IR spectra from Figure 3 in the region between 260 and $1000 \mathrm{~cm}^{-1}$ is shown in Figure 5. The $\mathrm{IR}^{2} \mathrm{MS}^{2}$ spectrum of $6 \mathrm{E} \cdot \mathrm{H}_{2}$ (trace $\mathrm{E}$ in Figure 5) reveals a rather complex absorption pattern with at least five groups of absorption bands $\left(\mathrm{a}^{\prime \prime}{ }_{15}-\mathrm{a}^{\prime \prime}{ }_{19}\right)$ of varying width. The IR band intensities are again qualitatively reproduced by the simulated anharmonic spectrum of $6 \mathrm{E} \cdot \mathrm{H}_{2}$ (trace $\mathrm{D}$ ), but the band positions are systematically predicted too high in energy. At the highest energy a $\mathrm{H}_{3} \mathrm{O}^{+}$libration $\left(\mathrm{a}_{15}^{\prime \prime}, 831 \mathrm{~cm}^{-1}\right)$ is observed. This is followed by two groups of $\mathrm{AD}-\mathrm{H}_{2} \mathrm{O}$ librational bands $\left(a^{\prime \prime}{ }_{16}\right.$ and $\mathrm{a}^{\prime \prime}{ }_{17}$ ) in the $775-450 \mathrm{~cm}^{-1}$ region, of which the absorption at higher (lower) energies corresponds to a frustrated rotation of the $\mathrm{AD}$ water molecules parallel (perpendicular) to the plane spanned by the three $\mathrm{H}$-atoms of the hydronium ion. HB stretching modes are observed below $400 \mathrm{~cm}^{-1}$. The sharp doublet at $358 / 373 \mathrm{~cm}^{-1}\left(\mathrm{a}^{\prime \prime}{ }_{18}\right)$, predicted at $385 / 405 \mathrm{~cm}^{-1}$, is assigned to frustrated translations of the hydrated hydronium ion. The corresponding IR-active harmonic normal modes are schematically shown in part A of Figure 5. These "translational" bands correspond to the symmetric and antisymmetric combination of the two $\mathrm{HB}$ stretches involving $\mathrm{H}_{3} \mathrm{O}^{+}$and the two $\mathrm{AD}$ water molecules. The third $\mathrm{HB}$ stretch involving $\mathrm{H}_{3} \mathrm{O}^{+}$and the terminal water molecule is predicted below $300 \mathrm{~cm}^{-1}$. We indeed find evidence for an intense band centered at $279 \mathrm{~cm}^{-1}\left(\mathrm{a}^{\prime \prime}{ }_{19}\right)$, which we assign to this $\mathrm{HB}$ stretching mode, but it may also contain contributions from terminal water wagging modes, which are expected in the same spectral range, but with lower IR intensity. The observation of isomer-specific bands as low as $358 \mathrm{~cm}^{-1}$ is important, as it demonstrates that the $\mathrm{IR}^{2} \mathrm{MS}^{2}$ technique remains isomer-selective down to a photon energy that is comparable to the dissociation limit $\left(D_{0}\right)$ of the complex (see Supporting Information). For $6 \mathrm{Z} \cdot \mathrm{H}_{2}$ the agreement between the experimental and the anharmonic spectra below $1000 \mathrm{~cm}^{-1}$ is less satisfactory. While band $\mathrm{a}^{\prime}{ }_{19}$ is reproduced and attributed, similar to $\mathrm{a}_{19}{ }_{19}$ of $6 \mathrm{E} \cdot \mathrm{H}_{2}$, to $\mathrm{HB}$-stretch and terminal waterwagging modes, the intensities of bands $a^{\prime}{ }_{15}$ to $a^{\prime}{ }_{17}$ are underestimated. Bands $\mathrm{a}^{\prime}{ }_{16}$ and $\mathrm{a}^{\prime}{ }_{17}$ are similar in shape and position to bands $\mathrm{a}^{\prime \prime}{ }_{16}$ and $\mathrm{a}^{\prime \prime}{ }_{17}$ (trace $\mathrm{E}$ in Figure 5), and

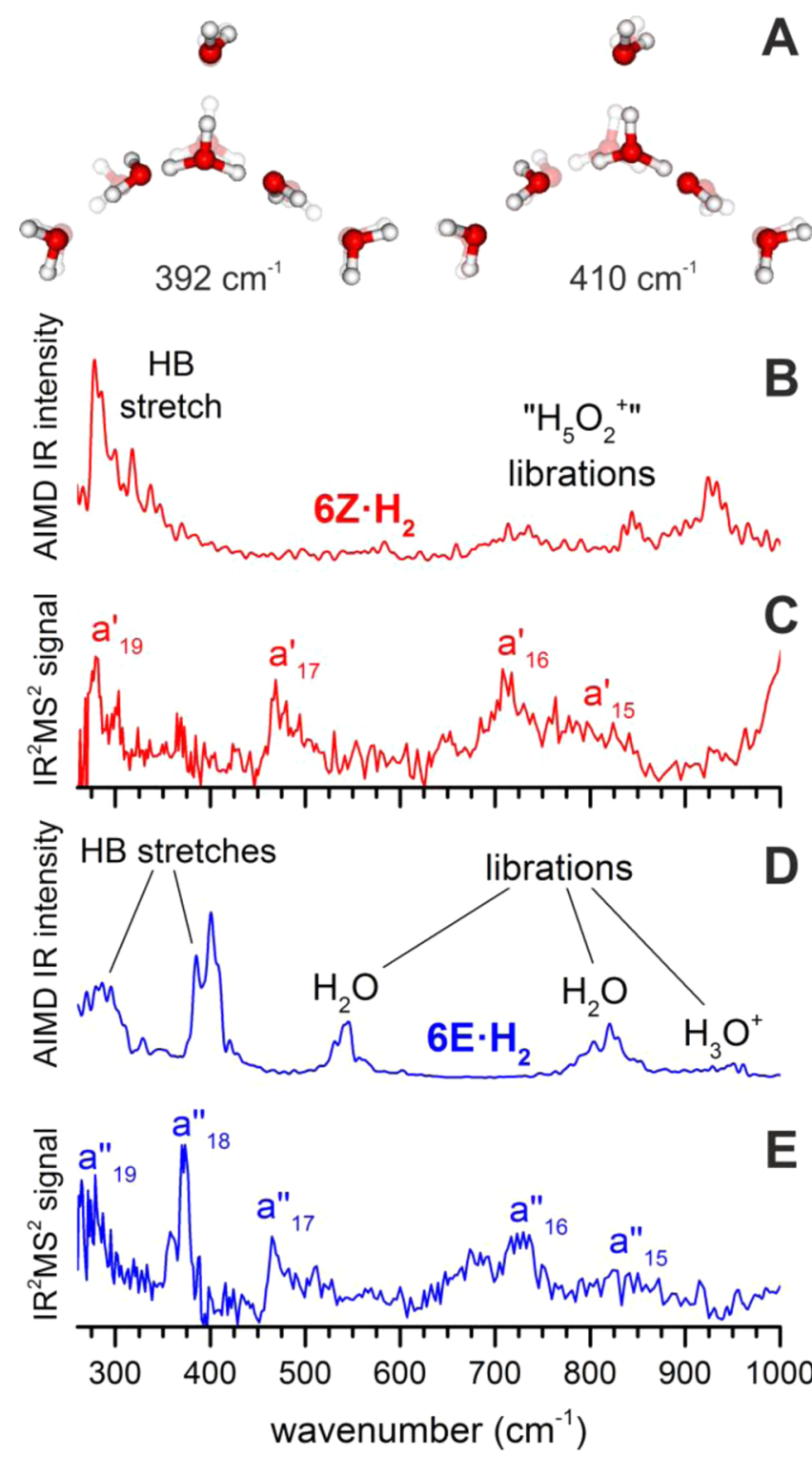

Figure 5. Schematic of the two characteristic hydrogen bond (HB) stretching normal modes and $\mathrm{PBE}+\mathrm{vdW}$ harmonic frequencies of $6 \mathrm{E}$ assigned to the two components of band $\mathrm{a}^{\prime \prime}{ }_{18}$ (A). For clarity, the corresponding motion without $\mathrm{H}_{2}$ attached is shown. Expanded view of the calculated (AIMD, B and D) and experimental (C and E) IR spectra from Figure 3 in the HB stretching and librational region.

therefore a tentative assignment of these bands to $\mathrm{H}_{2} \mathrm{O}$ librations involving the $\mathrm{H}_{2} \mathrm{O}$ moieties of $\mathrm{H}_{5} \mathrm{O}_{2}{ }^{+}$is reasonable.

Finally, it is interesting to compare the IR fingerprints of the Zundel-type and Eigen-type isomers of the protonated water hexamer in the gas phase (traces $\mathrm{C}$ and $\mathrm{D}$ in Figure 3 ) to the IR spectrum of $\mathrm{H}^{+}(a q)$ in solution. To this end the IR spectrum from ref 5 , obtained by a subtraction procedure from the IR spectrum of an aqueous solution of $0.75 \mathrm{M} \mathrm{HNO}_{3}$, is also shown in Figure 3 (trace A). It reveals four broad bands at 3146 $\left(b_{1}\right), 1747\left(b_{3}\right), 1198\left(b_{4}\right)$, and $672 \mathrm{~cm}^{-1}\left(b_{5}\right)$, as well as a shoulder at $2855 \mathrm{~cm}^{-1}\left(b_{2}\right)$. These five characteristic features were attributed to the peripheral $\mathrm{O}-\mathrm{H}$ stretching modes $\left(\mathrm{b}_{1}\right)$, the $\mathrm{O}-\mathrm{H}$ stretching $\left(b_{2}\right)$, bending $\left(b_{3}\right)$ and torsional $\left(b_{5}\right)$ modes of the $\mathrm{H}_{2} \mathrm{O}$ moieties in $\mathrm{H}_{5} \mathrm{O}_{2}{ }^{+}$, as well as the antisymmetric stretching mode involving the shared proton $\left(b_{4}\right)$ of a Zundel-type isomer with exceptionally long $\mathrm{O} \cdots \mathrm{O}$ 
separation. ${ }^{5}$ Taking into consideration that the free $\mathrm{O}-\mathrm{H}$ stretches (bands $a_{2}$ and $a_{4}$ in Figure 3 ) are absent in the solution phase data and that bands may be significantly thermally broadened at room temperature compared to the bands observed in the spectra of the clusters at cryogenic temperatures, trace A agrees surprisingly well with trace C, confirming the applicability of these protonated water clusters as model systems for testing computational models that ultimately try to describe $\mathrm{H}^{+}(a q)$ in solution.

\section{CONCLUSIONS}

To summarize, the present experimental approach combined with AIMD simulations allows us to spectroscopically isolate and assign the IR fingerprints of the Zundel and Eigen isomers of the protonated water hexamer down into the terahertz region of the electromagnetic spectrum. Experimental information, in particular, on the "translation" bands involving HB stretching motion, represents a first critical step toward understanding the proton transfer mechanism in this prototypical system, in particular, the vehicular component related to the translational diffusion of the hydrated proton solvation structure. ${ }^{6}$ The present results are also important for planning experiments that eventually will yield information on the barrier heights involved in this process. ${ }^{57}$ We observe that anharmonicities of the potential energy surface play a significant role even at low temperatures for these protonated water clusters and are the cause of the different widths of the observed IR bands. For a superior agreement between experiment and simulation, we propose to include nuclear quantum effects in the theoretical evaluation of IR spectra, which should also help to recover the experimental broadening at lower temperatures, i.e., closer to the experimental temperature.

\section{ASSOCIATED CONTENT}

\section{S Supporting Information}

Additional computational details. MP2 and $\mathrm{PBE}+\mathrm{vdW}$ relative energies of $6 \mathrm{Z}$ and $6 \mathrm{E}$ (Table S1), as well as $6 \mathrm{Z} \cdot \mathrm{H}_{2}$ and $6 \mathrm{E} \cdot \mathrm{H}_{2}$ (Table S2). Calculated anharmonic IR spectra of the bare $6 \mathrm{Z}$ and $6 \mathrm{E}$ (Figure S1). Calculated harmonic and anharmonic IR spectrum of $6 \mathrm{Z} \cdot \mathrm{H}_{2}$ (Figure S2), with focus on the region below $1000 \mathrm{~cm}^{-1}$. VDOS of $6 \mathrm{Z} \cdot \mathrm{H}_{2}$ with projected VDOS on the normal modes giving rise to the anharmonic peak at $950 \mathrm{~cm}^{-1}$ (Figure S3). PBE+vdW harmonic normal modes frequencies and intensities of $6 \mathrm{Z}, 6 \mathrm{Z} \cdot \mathrm{H}_{2}, 6 \mathrm{E}$, and $6 \mathrm{E} \cdot \mathrm{H}_{2}$ (Table $\mathrm{S} 3$ and Figure S4). This material is available free of charge via the Internet at http://pubs.acs.org.

\section{AUTHOR INFORMATION}

\section{Corresponding Author}

asmis@fhi-berlin.mpg.de; blum@fhi-berlin.mpg.de

Notes

The authors declare no competing financial interest.

\section{ACKNOWLEDGMENTS}

We thank the Stichting voor Fundamenteel Onderzoek der Materie (FOM) for beam time at FELIX and the FELIX staff for support and assistance. This research is funded by the European Community's Seventh Framework Programme (FP7/2007-2013) Grant No. 226716.

\section{REFERENCES}

(1) Cukierman, S. Biochim. Biophys. Acta, Bioenerg. 2006, 1757, 876.

(2) Eigen, M. Angew. Chem., Int. Ed. 1964, 3, 1.

(3) Zundel, G. In The Hydrogen Bond-Recent Developments in Theory and Experiments; Schuster, P., Zundel, G., Sandorf, C., Eds.; North-Holland: Amsterdam, 1976; p 683.

(4) Vuilleumier, R.; Borgis, D. J. Chem. Phys. 1999, 111, 4251.

(5) Stoyanov, E. S.; Stoyanova, I. V.; Reed, C. A. Chem. Sci. 2011, 2, 462.

(6) Knight, C.; Voth, G. A. Acc. Chem. Res. 2012, 45, 101.

(7) Keutsch, F. N.; Saykally, R. J. Proc. Natl. Acad. Sci. U. S. A. 2001, 98, 10533.

(8) Saykally, R. J.; Wales, D. J. Science 2012, 336, 814.

(9) Perez, C.; Muckle, M. T.; Zaleski, D. P.; Seifert, N. A.; Temelso, B.; Shields, G. C.; Kisiel, Z.; Pate, B. H. Science 2012, 336, 897.

(10) Headrick, J. M.; Diken, E. G.; Walters, R. S.; Hammer, N. I.; Christie, R. A.; Cui, J.; Myshakin, E. M.; Duncan, M. A.; Johnson, M. A.; Jordan, K. D. Science 2005, 308, 1765.

(11) Elliott, B. M.; Relph, R. A.; Roscioli, J. R.; Bopp, J. C.; Gardenier, G. H.; Guasco, T. L.; Johnson, M. A. J. Chem. Phys. 2008, 129, 094303.

(12) Leavitt, C. M.; Wolk, A. B.; Fournier, J. A.; Kamrath, M. Z.; Garand, E.; Van Stipdonk, M. J.; Johnson, M. A. J. Phys. Chem. Lett. 2012, 3, 1099.

(13) Jiang, J. C.; Wang, Y. S.; Chang, H. C.; Lin, S. H.; Lee, Y. T.; Niedner-Schatteburg, G.; Chang, H. C. J. Am. Chem. Soc. 2000, 122, 1398.

(14) Mizuse, K.; Fujii, A. Phys. Chem. Chem. Phys. 2011, 13, 7129.

(15) Vendrell, O.; Gatti, F.; Meyer, H.-D. Angew. Chem., Int. Ed. 2007, 46, 6918.

(16) Kaledin, M.; Kaledin, A. L.; Bowman, J. M.; Ding, J.; Jordan, K. D. J. Phys. Chem. A 2009, 113, 7671.

(17) Baer, M.; Marx, D.; Mathias, G. Angew. Chem., Int. Ed. 2010, 49, 7346.

(18) Park, M.; Shin, I.; Singh, N. J.; Kim, K. S. J. Phys. Chem. A 2007, 111, 10692.

(19) Dietrick, S. M.; Iyengar, S. S. J. Chem. Theory Comput. 2012, 8, 4876.

(20) Iyengar, S. S.; Petersen, M. K.; Day, T. J. F.; Burnham, C. J.; Teige, V. E.; Voth, G. A. J. Chem. Phys. 2005, 123, 084309.

(21) Schwarz, H. A. J. Chem. Phys. 1977, 67, 5525.

(22) Yeh, L. I.; Okumura, M.; Myers, J. D.; Price, J. M.; Lee, Y. T. J. Chem. Phys. 1989, 91, 7319.

(23) Lin, C. K.; Wu, C. C.; Wang, Y. S.; Lee, Y. T.; Chang, H. C.; Kuo, J. L.; Klein, M. L. Phys. Chem. Chem. Phys. 2005, 7, 938.

(24) Wu, C. C.; Lin, C. K.; Chang, H. C.; Jiang, J. C.; Kuo, J. L.; Klein, M. L. J. Chem. Phys. 2005, 122, 074315.

(25) Shin, J. W.; Hammer, N. I.; Diken, E. G.; Johnson, M. A.; Walters, R. S.; Jaeger, T. D.; Duncan, M. A.; Christie, R. A.; Jordan, K. D. Science 2004, 304, 1137.

(26) Douberly, G. E.; Walters, R. S.; Cui, J.; Jordan, K. D.; Duncan, M. A. J. Phys. Chem. A 2010, 114, 4570.

(27) Mizuse, K.; Mikami, N.; Fujii, A. Angew. Chem., Int. Ed. 2010, 49, 10119.

(28) Mizuse, K.; Fujii, A. J. Phys. Chem. A 2012, 116, 4868.

(29) Yeh, L. I.; Lee, Y. T.; Hougen, J. T. J. Mol. Spectrosc. 1994, 164, 473.

(30) Asmis, K. R.; Pivonka, N. L.; Santambrogio, G.; Brummer, M.; Kaposta, C.; Neumark, D. M.; Woste, L. Science 2003, 299, 1375.

(31) Hammer, N. I.; Diken, E. G.; Roscioli, J. R.; Johnson, M. A.; Myshakin, E. M.; Jordan, K. D.; McCoy, A. B.; Huang, X.; Bowman, J. M.; Carter, S. J. Chem. Phys. 2005, 122, 244301.

(32) Guasco, T. L.; Elliott, B. M.; Johnson, M. A.; Ding, J.; Jordan, K. D. J. Phys. Chem. Lett. 2010, 1, 2396.

(33) Relph, R. A.; Guasco, T. L.; Elliott, B. M.; Kamrath, M. Z.; McCoy, A. B.; Steele, R. P.; Schofield, D. P.; Jordan, K. D.; Viggiano, A. A.; Ferguson, E. E.; Johnson, M. A. Science 2010, 327, 308.

(34) Dian, B. C.; Longarte, A.; Zwier, T. S. Science 2002, 296, 2369. 
(35) Chin, W.; Dognon, J. P.; Canuel, C.; Piuzzi, F.; Dimicoli, I.; Mons, M.; Compagnon, I.; von Helden, G.; Meijer, G. J. Chem. Phys. 2005, 122 (054317), 1.

(36) Stearns, J. A.; Boyarkin, O. V.; Rizzo, T. R. J. Am. Chem. Soc. 2007, 129, 13820.

(37) Cocinero, E. J.; Carcabal, P.; Vaden, T. D.; Simons, J. P.; Davis, B. G. Nature 2011, 469, 76.

(38) Abo-Riziq, A.; Grace, L.; Crews, B.; Callahan, M. P.; van Mourik, T.; de Vries, M. S. J. Phys. Chem. A 2011, 115, 6077.

(39) Kebarle, P.; Searles, S. K.; Zolla, A.; Scarboro, J.; Arshadi, M. J. Am. Chem. Soc. 1967, 89, 6393.

(40) Lau, Y. K.; Ikuta, S.; Kebarle, P. J. Am. Chem. Soc. 1982, 104, 1462 .

(41) Okumura, M.; Yeh, L. I.; Myers, J. D.; Lee, Y. T. J. Chem. Phys. 1986, 85, 2328.

(42) Cheng, T. C.; Bandyopadhyay, B.; Mosley, J. D.; Duncan, M. A. J. Am. Chem. Soc. 2012, 134, 13046.

(43) Goebbert, D. J.; Meijer, G.; Asmis, K. R. AIP Conf. Proc. 2009, 1104, 22.

(44) Goebbert, D. J.; Garand, E.; Wende, T.; Bergmann, R.; Meijer, G.; Asmis, K. R.; Neumark, D. M. J. Phys. Chem. A 2009, 113, 7584.

(45) Oepts, D.; van der Meer, A. F. G.; van Amersfoort, P. W. Infrared Phys. Technol. 1995, 36, 297.

(46) Bosenberg, W. R.; Guyer, D. R. J. Opt. Soc. Am. B 1993, 10, 1716

(47) Brümmer, M.; Kaposta, C.; Santambrogio, G.; Asmis, K. R. J. Chem. Phys. 2003, 119, 12700.

(48) Goebbert, D. J.; Wende, T.; Bergmann, R.; Meijer, G.; Asmis, K. R. J. Phys. Chem. A 2009, 113, 5874.

(49) Blum, V.; Gehrke, R.; Hanke, F.; Havu, P.; Havu, V.; Ren, X.; Reuter, K.; Scheffler, M. Comput. Phys. Commun. 2009, 180, 2175.

(50) Perdew, J. P.; Burke, K.; Ernzerhof, M. Phys. Rev. Lett. 1996, 77, 3865.

(51) Tkatchenko, A.; Scheffler, M. Phys. Rev. Lett. 2009, 102, 073005.

(52) Chutia, S.; Rossi, M.; Blum, V. J. Phys. Chem. B 2012, 116, 14788.

(53) Vendrell, O.; Gatti, F.; Meyer, H. D. J. Chem. Phys. 2007, 127, 184303.

(54) Roscioli, J. R.; McCunn, L. R.; Johnson, M. A. Science 2007, 316, 249.

(55) Kulig, W.; Agmon, N. Nat. Chem. 2012, 5, 29.

(56) Agostini, F.; Vuilleumier, R.; Ciccotti, G. J. Chem. Phys. 2011, 134, 084302.

(57) Relph, R. A.; Elliott, B. M.; Weddle, G. H.; Johnson, M. A.;

Ding, J.; Jordan, K. D. J. Phys. Chem. A 2009, 113, 975. 